\title{
APLICAÇÃO DE COMPOSTO ORGÂNICO E ADUBO QUÍMICO NO FEIJOEIRO E SEU EFEITO RESIDUAL SOBRE A CULTURA DO MILHO
}

\author{
Allan Hisashi Nakao ${ }^{1 *}$, Ricardo Antonio Ferreira Rodrigues ${ }^{2}$, Marcelo Fernando Pereira \\ Souza $^{3}$, Lourdes Dickmann ${ }^{4}$, Gabriela Christal Catalani ${ }^{5}$, Daniela Capelas Centeno ${ }^{6}$

\footnotetext{
${ }^{1}$ Doutorando do Programa de Pós-Graduação em Agronomia, FEIS/UNESP, Câmpus de Ilha Solteira, SP. *Email: allanhisashinakao@gmail.com.

${ }^{2}$ Professor Dr. do Departamento de Fitossanidade Engenharia Rural e Solos, FEIS/UNESP, Câmpus de Ilha Solteira, SP.

${ }^{3}$ Professor Dr. da Escola Técnica de Alta Floresta, MT.

${ }^{4}$ Doutoranda do Programa de Pós-Graduação em Agronomia, FEIS/UNESP, Câmpus de Ilha Solteira, SP.

${ }^{5}$ Doutoranda do Programa de Pós-Graduação em Proteção de Plantas, FCA/UNESP, Câmpus de Botucatu, SP.

${ }^{6}$ Mestranda do Programa de Pós-Graduação em Agronomia, FEIS/UNESP, Câmpus de Ilha Solteira, SP.
}

RESUMO: Os fertilizantes orgânicos, quando bem aproveitados, trazem grandes benefícios disponibilizando nutrientes ao solo tanto na cultura principal, quanto em sucessão. Dessa forma, o objetivo deste trabalho foi verificar a extração de nutrientes, desenvolvimento e produtividade do feijoeiro de inverno e do milho em sucessão, bem como avaliar os atributos químicos do solo, obtido a partir da adubação orgânica e mineral do feijoeiro. Realizou-se em área da UNESP, campus de Ilha Solteira, um ensaio experimental com delineamento em blocos casualizados, com 4 repetições em esquema fatorial 4 x 2, num Latossolo Vermelho distrófico. Os tratamentos constituíram-se de quatro doses do composto orgânico $(0,2,4$ e 6 $\mathrm{t} \mathrm{ha}^{-1}$ ) e dois tratamentos com adubos químicos. Não houve efeito da adubação orgânica nos componentes de produção do feijoeiro, nem efeito residual no milho. Entretanto, a aplicação do adubo orgânico alterou os teores foliares de $\mathrm{Ca}$ e $\mathrm{Mg}$ na cultura do feijoeiro, além do $\mathrm{P}$, $\mathrm{Ca}$ e $\mathrm{S}$ no milho. A aplicação de composto orgânico ao solo incrementou os teores de nutrientes do solo, elevando principalmente os teores de P e K.

Palavras-chave: Adubação orgânica. Fertilidade do solo. Sistema plantio direto.

\section{APPLICATION OF ORGANIC COMPOUND AND CHEMICAL FERTILIZER IN THE BEAN AND ITS RESIDUAL EFFECT ON THE MAIZE CROP}

\begin{abstract}
Organic fertilizers, when well used, can bring great benefits to the soil providing nutrients for both the main crop and its succession. Therefore, the aim of this study was to evaluate the nutrient extraction, development and yield of winter common bean and maize in succession, and to assess the soil chemical properties, obtained from organic and mineral fertilizer bean. The study was developed at UNESP Ilha Solteira Campus experimental farm, using a complete randomized block design with four replications in a factorial $4 \times 2$, in an Oxisol. The treatments consisted of four rates of organic compound ( 0 , 2, 4 and $6 \mathrm{t} \mathrm{ha}^{-1}$ ) and two treatments with chemical fertilizers. There was no effect of organic fertilization on common bean production components as well as no residual effect on maize.
\end{abstract}

Cultura Agronômica, Ilha Solteira, v.25, n.4, p.387-400, 2016 
However, the application of organic fertilizer changed $\mathrm{Ca}$ and $\mathrm{Mg}$ leaf content on common beans, in addition to $\mathrm{P}, \mathrm{Ca}$ and $\mathrm{S}$ on maize. The application of organic compound to soil increased the levels of soil nutrients, mainly by raising the levels of $\mathrm{P}$ and $\mathrm{K}$.

Key words: Conservation tillage. Organic fertilization. Soil fertility.

\section{INTRODUÇÃO}

A utilização de composto orgânico em solos agrícolas, como adubos orgânicos ou condicionador do solo, tem crescido nos últimos anos no Brasil, por conta do acentuado crescimento no volume de resíduos orgânicos gerados por parte da população, problemas relacionados à degradação do solo, do ambiente e, sobretudo a saúde humana. Assim, a busca por pesquisas que visam tecnologias alternativas que favoreçam a utilização dos resíduos e aumente a produtividade das culturas de forma sustentável tem sido amplamente debatidas e sugeridas para adoção em sistemas agrícolas.

Com o crescimento populacional os sistemas agropecuários e agroindustriais fez com que aumentassem sua produção a fim de suprir a demanda por alimentos. Dessa forma, a produção constante e inesgotável de resíduos tem gerado grande problema de ordem social, econômica e ecológica (VERAS; POVINELLI, 2004). Portanto diversos autores vem contribuindo com pesquisas para a minimização do impacto ambiental do uso de resíduos. Dentre as várias fontes orgânicas geradas com potencial para utilização na agricultura destacam-se os resíduos líquidos de efluentes da agroindústria de carnes (MORAES et al., 2012), composto de lixo urbano (KROB et al., 2011), o lodo de esgoto (RIBEIRINHO et al., 2012), dejetos bovinos e cama de frango (GUARESCHI et al., 2013) e dejetos líquidos de suínos (SARTOR et al., 2012). Entretanto, ainda existe carência de estudos a respeito das alterações dos atributos químicos do solo, visando uma melhora e na busca por alternativas que minimizem os impactos ambientais de disposições inadequadas destes resíduos sobre o solo.

O Brasil é um dos maiores consumidores e produtores de feijão e milho do mundo. No entanto a produtividade brasileira está muito baixa em relação ao potencial que essas culturas podem atingir. As buscas por elevação dos níveis atuais de produtividade e redução nos custos de produção são escassos, novas tecnologias estão sendo incorporadas aos sistemas de produção de feijão e milho no Brasil, como a utilização de compostos orgânicos de agroindústrias, na adubação das culturas.

Além disso, a adubação orgânica é uma prática considerada simples, pois aproveita restos culturais e agroindustriais, se apresentando como uma alternativa de baixo custo. De acordo com Vidigal et al. (2010), a elevação nos preços dos insumos agrícolas, dentre eles, os fertilizantes minerais de fontes solúveis fizeram com que, houvesse maior procura por fontes alternativas de nutrientes. Diante do exposto, o trabalho teve como objetivo verificar a extração de nutrientes, desenvolvimento e produtividade do feijoeiro de inverno e milho em

Cultura Agronômica, Ilha Solteira, v.25, n.4, p.387-400, 2016 
sucessão, bem como dos atributos químicos de um Latossolo Vermelho distrófico obtido a partir da adubação orgânica e/ou mineral do feijoeiro de inverno.

\section{MATERIAL E MÉTODOS}

O experimento foi desenvolvido na Fazenda de Ensino, Pesquisa e Extensão, pertencente à Faculdade de Engenharia, Campus de Ilha Solteira (FE/UNESP), área de Produção Vegetal, localizada no município de Selvíria, MS (20²0'S e $51^{\circ} 24^{\prime}$ W, altitude de 335 m). O tipo climático é Aw, segundo classificação de Köppen, caracterizado como tropical úmido com estação chuvosa no verão e seca no inverno. A precipitação média anual foi de $1370 \mathrm{~mm}$, com temperatura média de $23,5^{\circ} \mathrm{C}$ e umidade relativa do ar (UR\%) entre $70-80 \%$.

O solo da área em estudo foi classificado como Latossolo Vermelho distrófico de textura argilosa. Realizou-se a caracterização química do solo na camada de $0,0-0,20 \mathrm{~m}$ anterior à instalação do experimento e os valores dos atributos químicos foram os seguintes: $\mathrm{pH}\left(\mathrm{CaCl}_{2}\right)=5,0 ; \mathrm{M} . \mathrm{O} .=17 \mathrm{~g} \mathrm{dm}^{-3} ; \mathrm{H}+\mathrm{Al}=17 \mathrm{mmol}_{\mathrm{c}} \mathrm{dm}^{-3} ; \mathrm{P}($ resina $)=25 \mathrm{mg} \mathrm{dm}^{-3} ; \mathrm{K}, \mathrm{Ca}$ e $\mathrm{Mg}=1,0 ; 19$ e $13 \mathrm{mmol}_{\mathrm{c}} \mathrm{dm}^{-3}$; respectivamente, e $\mathrm{V}=66 \%$.

O delineamento experimental foi o de blocos ao acaso com quatro repetições em esquema fatorial $4 \times 2$. Os tratamentos constituíram-se de quatro doses de composto orgânico $\left(0,2,4\right.$ e $\left.6 \mathrm{t} \mathrm{ha}^{-1}\right)$ e dois tratamentos com adubação mineral ( 0 e $50 \%$ da dose recomendada para a cultura do feijoeiro de inverno). Com base nas características químicas do solo e na tabela de recomendação para a cultura do feijoeiro no Estado de São Paulo (CANTARELLA et al., 1997), a adubação de base em sulco de semeadura foi de $250 \mathrm{~kg} \mathrm{ha}^{-1}$ do formulado 430-10.

O composto orgânico utilizado no estudo é produto resultante dos resíduos oriundos dos processos produtivos de agroindústrias como: frigoríficos de bovinos, aves, suínos (farinha de osso, farinha de sangue, lodo proveniente da decantação em lagoas anaeróbicas e do bolo ruminal), além de esterco vindos de confinamentos e subprodutos de usinas de açúcar/etanol (Organosolví - Coroados/SP).

Para quantificação da dose do composto orgânico foi realizada análise química para $\mathrm{pH}$, M.O e macronutrientes, cujos resultados foram: $\mathrm{pH}\left(\mathrm{CaCl}_{2}\right)=7,1 ; \mathrm{M} . \mathrm{O} .=118 \mathrm{~g} \mathrm{dm}^{-3} ; \mathrm{N}, \mathrm{P}$, $\mathrm{K}^{+}, \mathrm{Ca}^{2+}, \mathrm{Mg}^{2+}, \mathrm{Al}^{+3}$ e $\mathrm{SO}_{4}^{-2}=12,4 ; 3,4 ; 8,5 ; 11,1 ; 2,1 ; 0$ e $40 \mathrm{~g} \mathrm{~kg}^{-1}$; respectivamente e micronutrientes: $\mathrm{Fe}, \mathrm{Cu}, \mathrm{Mn}, \mathrm{B}$ e $\mathrm{Zn}=2.423 ; 32 ; 298 ; 157$ e $61 \mathrm{mg} \mathrm{kg}^{-1}$; respectivamente com umidade de $22 \%$ e relação $\mathrm{C} / \mathrm{N}$ de 11,77 . Após a análise dos teores nutricionais do composto orgânico foram definidas as 4 doses $\left(0,2,4\right.$ e 6 toneladas do composto por ha $\left.{ }^{-1}\right)$, com base na recomendação para adubação nitrogenada $(\mathrm{N})$.

O composto orgânico foi aplicado a lanço em 25/05/2013 de modo manual e superficialmente sobre os restos culturais do milho, cultivado anteriormente ao feijoeiro de inverno. Sendo que a área estava sendo conduzida em sistema plantio direto há 12 anos. 
As parcelas foram constituídas por 7 linhas de feijoeiro com $5 \mathrm{~m}$ de comprimento, em espaçamento de $0,45 \mathrm{~m}$ entre si, perfazendo um total de $18 \mathrm{~m}^{2}$ e com área útil de $12,5 \mathrm{~m}^{2} . \mathrm{O}$ cultivar utilizado foi o Pérola do grupo carioca, com porte semiprostrado. Realizou-se adubação de cobertura comum a todos os tratamentos, aos 30 dias após a emergência das plantas no estádio $\mathrm{V}_{4}$ (quarta folha trifoliada), com aplicação de $92 \mathrm{~kg} \mathrm{ha}^{-1} \mathrm{de} \mathrm{N}$, na forma de ureia.

Para avaliação do estado nutricional (teores dos macronutrientes) do feijoeiro, coletouse 30 trifólios de cada parcela, quando estas se encontravam no estádio de florescimento pleno. As folhas foram lavadas e posteriormente acondicionadas em sacos de papel e secas em estufa com circulação forçada de ar a $65^{\circ} \mathrm{C}$, até atingir massa constante. Em seguida, foram moídas em moinho tipo Willey e submetidas à análise química conforme metodologia proposta por Malavolta et al. (1997).

A colheita do feijoeiro foi realizada manualmente em agosto de 2013, aos 93 dias após a emergência das plantas (DAE). Foram avaliados os componentes da produção em 10 plantas, coletadas ao acaso dentro da área útil da parcela experimental. Para determinação da produtividade de grãos (PROD) foram coletadas todas as plantas da área útil da parcela, trilhadas e os grãos pesados para correção da umidade para $13 \%$.

Após a colheita do feijão foram avaliados por meio de análises químicas os efeitos da adubação orgânica no solo, sendo que, em cada parcela experimental, retiraram-se 10 subamostras de solo na camada de 0-0,10 e 0,10-0,20 m na área de aplicação do composto para formar uma amostra composta por unidade experimental, com auxílio de um trado de rosca. As amostras coletadas após o cultivo do feijoeiro foram encaminhadas para o Laboratório de Fertilidade do Solo da UNESP de Ilha Solteira para a determinação dos teores de potássio, fósforo, cálcio e magnésio, além do $\mathrm{pH}$, teor de matéria orgânica (M.O.) soma de bases (SB), capacidade de troca catiônica (CTC) e saturação por bases (V\%). As amostras foram secas em casa de vegetação e analisadas conforme a metodologia proposta por Raij et al. (2001).

No dia 09/12/2013, o milho (híbrido simples DKB 390 YG) foi semeado mecanicamente sobre a palhada do feijoeiro de inverno, visando mensurar o efeito residual do composto orgânico. As sementes foram depositadas a uma profundidade de aproximadamente $0,05 \mathrm{~m}$, em linhas espaçadas $0,90 \mathrm{~m}$ e com cerca de 5,4 sementes $\mathrm{m}^{-1}$.

A adubação de semeadura no milho foi realizada com a aplicação de $280 \mathrm{~kg} \mathrm{ha}^{-1}$ do formulado 8-28-16. A adubação de cobertura foi realizada em janeiro de 2014, quando o milho se encontrava no estádio V5 (cinco folhas totalmente desenvolvidas). Para isto, foram aplicados mecanicamente $126 \mathrm{~kg} \mathrm{ha}^{-1}$ de $\mathrm{N}$, na forma de sulfato de amônio. No período do florescimento, após a emissão da inflorescência feminina, coletaram-se o terço médio das dez folhas por parcela para determinação das concentrações de macronutrientes (MALAVOLTA et al., 1997). 
A colheita manual do milho, para avaliação dos componentes de produção e da produtividade de grãos (área útil da parcela), foi realizada em abril de 2014, aos 119 dias após a emergência (DAE) da cultura. Para determinação da produtividade de grãos (PROD) foram coletadas todas as plantas da área útil da parcela, trilhadas e os grãos pesados para correção da umidade para $13 \%$ (base úmida).

Os dados obtidos foram submetidos à análise de variância pelo teste $\mathrm{F}$, sendo as comparações entre os tratamentos efetuada por meio de análises de regressão para as doses do composto orgânico, e para o tratamento com a presença ou ausência do adubo químico a comparação de médias pelo teste de Tukey a 5\% de probabilidade. Para tanto foi utilizado o programa estatístico Sisvar (FERREIRA, 2003).

\section{RESULTADOS E DISCUSSÃO}

A aplicação do composto orgânico alterou os teores foliares de $\mathrm{Ca}$ e $\mathrm{Mg}$ do feijoeiro de inverno (Tabela 1). Assim como ocorreu para as características agronômicas e produtivas da cultura, não evidenciou-se efeitos da aplicação de metade da dose mineral recomendada para a cultura em relação ao controle (sem adubação mineral) para os macronutrientes avaliados. Entretanto, foi constatada diferença sobre o índice de clorofila foliar. Também, não se verificou alterações significativas da interação entre composto orgânico e adubação mineral.

Tabela 1. Média dos teores foliares de macronutrientes $\left(\mathrm{g} \mathrm{kg}^{-1}\right)$ do feijoeiro e índice de clorofila foliar (ICF), em função de doses do composto orgânico combinado ou não com adubação mineral em Selvíria, MS.

\begin{tabular}{|c|c|c|c|c|c|c|c|}
\hline \multirow{2}{*}{ Tratamento } & $\mathrm{N}$ & $\mathrm{P}$ & $\mathrm{K}$ & $\mathrm{Ca}$ & $\mathrm{Mg}$ & $S$ & ICF \\
\hline & \multicolumn{7}{|c|}{-------------------------------(g kg-1) ------------------------------- } \\
\hline \multicolumn{8}{|c|}{ Composto Orgânico $\left(\mathrm{t} \mathrm{ha}^{-1}\right)$} \\
\hline$\overline{0}$ & 33,53 & 3,17 & 18,81 & $27,59^{(1)}$ & $8,12^{(2)}$ & 2,55 & 40,41 \\
\hline 2 & 34,40 & 3,17 & 22,23 & 22,97 & 6,85 & 2,38 & 39,42 \\
\hline 4 & 34,59 & 3,07 & 20,53 & 22,68 & 6,09 & 3,08 & 38,17 \\
\hline 6 & 34,07 & 3,46 & 21,84 & 19,90 & 6,00 & 2,61 & 41,17 \\
\hline Teste $\mathrm{F}-(\mathrm{CO})$ & $0,15^{\mathrm{ns}}$ & $1,20^{\mathrm{ns}}$ & $2,10^{\mathrm{ns}}$ & $4,85^{*}$ & $6,16^{* *}$ & $1,49^{\mathrm{ns}}$ & $0,10^{\mathrm{ns}}$ \\
\hline$\overline{\mathrm{CV}(\%)}$ & 9,85 & 13,39 & 14,47 & 17,56 & 16,53 & 26,28 & 10,59 \\
\hline \multicolumn{8}{|l|}{ Adubo Mineral $\left(\mathrm{Kg} \mathrm{ha}^{-1}\right)$} \\
\hline Testemunha & 34,52 & 3,18 & 20,36 & 23,25 & 6,81 & 2,62 & $41,63 a$ \\
\hline $1 / 2$ dose Recomendado & 33,77 & 3,25 & 21,34 & 23,33 & 6,71 & 2,69 & $37,96 b$ \\
\hline Teste F (AM) & $0,40^{\mathrm{ns}}$ & $0,25^{\mathrm{ns}}$ & $0,83^{\mathrm{ns}}$ & $0,10^{\mathrm{ns}}$ & $0,06^{\mathrm{ns}}$ & $0,08^{\mathrm{ns}}$ & $6,06^{*}$ \\
\hline DMS & 2,47 & 0,31 & 2,21 & 2,98 & 0,81 & 0,51 & 3,09 \\
\hline Teste $\mathrm{F}-\mathrm{CO} \times \mathrm{AM}$ & $0,397^{\mathrm{ns}}$ & $1,26^{\mathrm{ns}}$ & $0,56^{\mathrm{ns}}$ & $0,96^{\mathrm{ns}}$ & $0,76^{\mathrm{ns}}$ & $1,19^{\mathrm{ns}}$ & $1,83^{\mathrm{ns}}$ \\
\hline
\end{tabular}

Cultura Agronômica, Ilha Solteira, v.25, n.4, p.387-400, 2016 
O teor de Ca nas folhas ficou dentro da faixa considerada como adequada por Raij et al. (1997) de 10 a $25 \mathrm{~g} \mathrm{~kg}^{-1}$, entretanto a testemunha apresentou valores acima da faixa 27,59 $\mathrm{g} \mathrm{kg}^{-1}$. Os valores exibidos para Ca se ajustaram em uma função linear com resposta negativa a aplicação do composto orgânico na superfície do solo antes da semeadura do feijoeiro. Assim, a aplicação do composto orgânico resultou num decréscimo, mesmo que discreto, nos teores de Ca.

$\mathrm{O}$ teor de $\mathrm{Mg}$ nas folhas foi superior nas plantas dos tratamentos testemunha, ficando acima da faixa considerada como adequada para o bom desenvolvimento da cultura do feijão de acordo com Raij et al. (1997). A partir do tratamento testemunha constatou-se redução nos valores de $\mathrm{Mg}$ encontrados nos tecidos foliares das plantas tratadas com composto orgânico. Entretanto, mesmo havendo redução nos valores, os teores do nutriente ficaram acima da faixa considerada como adequada para o bom desenvolvimento do feijoeiro (2,5 a 5,0 $\left.\mathrm{g} \mathrm{kg}^{-1}\right)$. Assim, é importante salientar que altos teores de $\mathrm{Mg}$, como os encontrados no presente estudo, podem pelo desbalanço nutricional afetar o pleno desenvolvimento da cultura (RAIJ et al., 1997).

Conforme os dados do índice de clorofila foliar, na Tabela 1, observa-se que a metade da dose do adubo químico diminuiu o teor de clorofila na folha. Contudo não houve correlação no incremento na produtividade do feijoeiro de inverno.

Tabela 2. Média dos valores de altura da planta (AP), altura de inserção da primeira vagem (AIPV), comprimento de vagem (CV), número de vagem por planta (NVP), número de grãos por vagem (NGV), massa cem grãos (M100) e produtividade de grãos (PROD) em função das doses do composto orgânico combinado ou não com adubação mineral sobre a cultura do feijão de inverno em Selvíria, MS.

\begin{tabular}{|c|c|c|c|c|c|c|c|}
\hline \multirow{2}{*}{ Tratamento } & AP & AIPV & $\mathrm{CV}$ & NVP & NGV & M100 & PROD \\
\hline & \multicolumn{3}{|c|}{-------------(cm)-------------- } & \multicolumn{2}{|c|}{---------(no $\left.{ }^{\circ}\right)--------$} & (g) & $\left(\mathrm{kg} \mathrm{ha}^{-1}\right)$ \\
\hline \multicolumn{8}{|c|}{ Composto Orgânico $\left(\mathrm{t} \mathrm{ha}^{-1}\right)$} \\
\hline 0 & 85,83 & 17,43 & 10,60 & 9,66 & 5,31 & 26,06 & 2942 \\
\hline 2 & 84,46 & 15,76 & 10,36 & 9,46 & 5,40 & 25,63 & 2973 \\
\hline 4 & 86,91 & 17,66 & 10,20 & 9,13 & 5,05 & 29,19 & 3037 \\
\hline 6 & 86,91 & 16,91 & 10,40 & 9,38 & 5,43 & 26,02 & 3043 \\
\hline \multicolumn{8}{|l|}{ Adubo Mineral $\left(\mathrm{kg} \mathrm{ha}^{-1}\right)$} \\
\hline Testemunha & 83,55 & 16,98 & 10,48 & 9,06 & 5,46 & 26,78 & 2918 \\
\hline $1 / 2$ dose Recomendado & 88,50 & 16,92 & 10,30 & 9,75 & 5,14 & 26,76 & 3081 \\
\hline Teste $\mathrm{F}-(\mathrm{CO})$ & $0,10^{\mathrm{ns}}$ & $0,72^{\mathrm{ns}}$ & $0,90^{\mathrm{ns}}$ & $0,16^{\mathrm{ns}}$ & $0,75^{\mathrm{ns}}$ & $1,41^{\mathrm{ns}}$ & $0,10^{\mathrm{ns}}$ \\
\hline Teste F - (AM) & $1,35^{\mathrm{ns}}$ & $0,10^{\mathrm{ns}}$ & $1,16^{\mathrm{ns}}$ & $1,58^{\mathrm{ns}}$ & $2,64^{\mathrm{ns}}$ & $0,09^{\mathrm{ns}}$ & $1,12^{\mathrm{ns}}$ \\
\hline Teste $\mathrm{F}-\mathrm{CO} \times \mathrm{AM}$ & $0,49^{\mathrm{ns}}$ & $1,12^{\mathrm{ns}}$ & $0,31^{\mathrm{ns}}$ & $0,56^{\mathrm{ns}}$ & $0,78^{\mathrm{ns}}$ & $1,41^{\mathrm{ns}}$ & $0,67^{\mathrm{ns}}$ \\
\hline$\overline{\mathrm{DMS}}(\mathrm{AM})$ & 8,84 & 2,09 & 0,35 & 1,13 & 0,41 & 2,90 & 320,94 \\
\hline$\overline{\mathrm{CV}}(\%)$ & 13,98 & 16,81 & 4,64 & 16,40 & 10,58 & 14,77 & 14,55 \\
\hline
\end{tabular}

Médias seguidas pela mesma letra na coluna, não diferem entre si pelo teste de Tukey a 5\% de probabilidade. ${ }^{* *}$ $\mathrm{e}^{*}$ : significativo ao nível de 1 e 5\% respectivamente. ${ }^{\text {ns: }}$ não significativo. Em que: CV: coeficiente de variação; DMS: diferença mínima significativa.

Cultura Agronômica, Ilha Solteira, v.25, n.4, p.387-400, 2016 
Quanto as características agronômicas, componentes da produção e produtividade de grãos do feijoeiro de inverno não houve efeito do composto orgânico (Tabela 2). $\mathrm{O}$ uso de metade da dose da adubação mineral na semeadura do feijoeiro não alterou as características agronômicas estudadas, não diferindo da testemunha (sem aplicação da fonte mineral). A interação composto orgânico e adubação mineral não promoveu efeitos sobre as características estudadas do feijoeiro de inverno.

Para os atributos químicos do solo a aplicação do composto orgânico promoveu alterações apenas nos teores de P (Tabela 3). Assim, como observado para a aplicação do composto orgânico, a utilização da metade da adubação mineral recomendada para a cultura do feijoeiro alterou os teores de $\mathrm{P}$ do solo. Não houve diferenças significativas para a interação entre a aplicação do composto orgânico e adubação mineral.

Tabela 3. Valores médios da análise de solo na camada de $0,00-0,10 \mathrm{~m}$ na cultura do feijoeiro adubada com composto orgânico e mineral. Selvíria, Mato Grosso do Sul. Safra 2013.

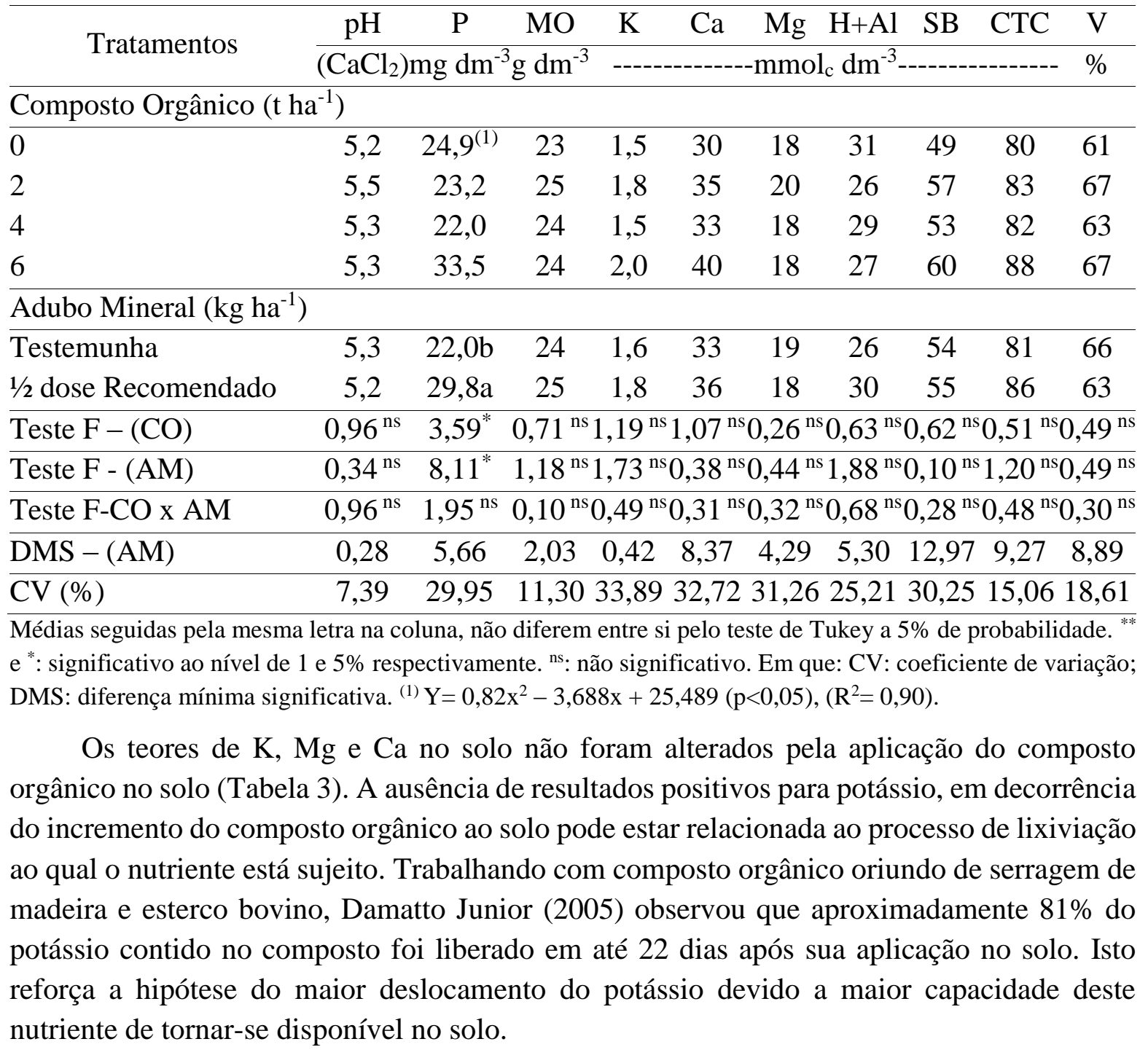

Cultura Agronômica, Ilha Solteira, v.25, n.4, p.387-400, 2016 
Mesmo com a aplicação de $6 \mathrm{t} \mathrm{ha}^{-1}$ do composto orgânico não houve alterações nos teores da matéria orgânica avaliados na camada de 0,0-0,10 m. As elevadas temperaturas típicas da região, aliadas à baixa precipitação e umidade, podem ter contribuído para uma elevada taxa de decomposição. Desta forma, alterações nos teores de MO do solo nas condições deste ensaio experimental seriam pouco prováveis, mesmo com doses mais elevadas do composto orgânico.

Os resultados exibidos para os teores de $\mathrm{P}$ do solo decorrentes da aplicação do composto orgânico se ajustaram em um modelo quadrático. Assim, melhores resultados para este atributo químico foram observados pela aplicação de $6 \mathrm{t} \mathrm{ha}{ }^{-1}$ do composto orgânico. Esses resultados sugerem que a adoção do composto orgânico a partir da referida dose promoveram incremento nos teores do P no solo, fornecendo-o suficientemente para suprir a demanda das plantas pelo nutriente.

Na camada de 0,10-0,20 m de profundidade, houve efeito dos tratamentos sobre os teores de potássio e cálcio. Verificou-se também que, a adubação mineral (metade da dose recomendada para a cultura do feijoeiro) incrementou os valores médios do potássio. Além disso, interações significativas entre a aplicação do composto orgânico e adubação mineral foram observados para $\mathrm{K}$ e Ca (Tabela 4).

Tabela 4. Valores médios da análise de solo na camada de 0,10-0,20 m na cultura do feijoeiro adubada com composto orgânico e mineral. Selvíria, Mato Grosso do Sul. Safra 2013.

\begin{tabular}{|c|c|c|c|c|c|c|c|c|c|c|}
\hline \multirow{2}{*}{ Tratamentos } & $\mathrm{pH}$ & $\mathrm{P}$ & $\mathrm{MO}$ & K & $\mathrm{Ca}$ & $\mathrm{Mg}$ & $\mathrm{H}+\mathrm{Al}$ & SB & CTC & $\mathrm{V} \%$ \\
\hline & \multicolumn{9}{|c|}{$\left(\mathrm{CaCl}_{2}\right) \mathrm{mg} \mathrm{dm}^{-3} \mathrm{~g} \mathrm{dm}^{-3}$} & $(\%)$ \\
\hline \multicolumn{11}{|c|}{ Composto Orgânico $\left(\mathrm{t} \mathrm{ha}^{-1}\right)$} \\
\hline 0 & 5,3 & 14,1 & 20 & $0,7^{(1)}$ & $27^{(2)}$ & 16 & 28 & 46,0 & 74,8 & 60 \\
\hline 2 & 5,4 & 15,8 & 20 & 0,7 & 24 & 16 & 25 & 42,9 & 68,2 & 62 \\
\hline 4 & 5,2 & 16,8 & 19 & 0,8 & 21 & 14 & 28 & 38,7 & 59,8 & 56 \\
\hline 6 & 5,0 & 14,2 & 18 & 0,9 & 18 & 12 & 30 & 34,7 & 64,9 & 51 \\
\hline \multicolumn{11}{|c|}{ Adubo Mineral $\left(\mathrm{kg} \mathrm{ha}^{-1}\right)$} \\
\hline Testemunha & 5,3 & 14,2 & 19,7 & $0,7 \mathrm{~b}$ & 23 & 15 & 27 & 43,3 & 67,0 & 60 \\
\hline $1 / 2$ dose Recomendado & 5,2 & 16,1 & 19,7 & $0,9 \mathrm{a}$ & 22 & 13 & 29 & 37,7 & 66,8 & 55 \\
\hline Teste $\mathrm{F}-(\mathrm{CO})$ & $1,14^{\mathrm{ns}}$ & $0,44^{\mathrm{ns}}$ & $1,60^{\mathrm{ns}}$ & $4,07^{*}$ & $6,50^{* *}$ & $1,17^{\mathrm{ns}}$ & $0,64^{\mathrm{ns}}$ & $1,13^{\mathrm{ns}}$ & $1,63^{\mathrm{ns}}$ & $1,07^{\mathrm{ns}}$ \\
\hline Teste F - (AM) & $1,33^{\mathrm{ns}}$ & $1,01^{\mathrm{ns}}$ & $0,10^{\mathrm{ns}}$ & $25,5^{* *}$ & $0,43^{\mathrm{ns}}$ & $1,55^{\mathrm{ns}}$ & $0,67^{\mathrm{ns}}$ & $1,41^{\mathrm{ns}}$ & $0,10^{\mathrm{ns}}$ & $1,15^{\mathrm{ns}}$ \\
\hline Teste F-CO x AM & $1,70^{\mathrm{ns}}$ & $0,94^{\mathrm{ns}}$ & $0,85^{\mathrm{ns}}$ & $5,26^{* *}$ & $3,07^{*}$ & $1,69^{\mathrm{ns}}$ & $0,51^{\mathrm{ns}}$ & $1,63^{\mathrm{ns}}$ & $2,30^{\mathrm{ns}}$ & $1,30^{\mathrm{ns}}$ \\
\hline$\overline{D M S}-(\mathrm{AM})$ & 0,31 & 3,99 & 0,97 & 0,09 & 3,46 & 3,33 & 5,20 & 9,78 & 10,22 & 9,44 \\
\hline $\mathrm{CV}(\%)$ & 8,09 & 35,81 & 6,72 & 15,14 & 19,86 & 30,79 & 25,25 & 32,79 & 20,78 & 22,26 \\
\hline
\end{tabular}

A ausência de resultados significativos para os teores de $\mathrm{P}$ pode estar relacionada ao fato deste nutriente apresentar baixa mobilidade no solo, não conseguindo percolar no perfil 
do solo para camadas mais profundas, acumulando superficialmente, assim diagnosticado na camada 0,0-0,10 $\mathrm{m}$ do experimento.

$\mathrm{O}$ teor de $\mathrm{K}$ apresentou aumentos significativos em função do incremento do composto orgânico, com efeito linear na camada de 0,10-0,20 m (Tabela 4). Em contrapartida, os resultados obtidos para o $\mathrm{Ca}$ apresentaram redução linear dos seus teores do solo em função da adição do composto, sendo que os maiores resultados foram constatados na testemunha (tratamento sem composto orgânico), enquanto que nas maiores doses do composto orgânico $\left(4\right.$ e $\left.6 \mathrm{t} \mathrm{ha}^{-1}\right)$ observaram-se os menores teores.

No desdobramento da interação entre composto orgânico e adubação mineral (Tabela 5) para o teor de $\mathrm{K}$ no solo, verificou-se diferenças significativas entre a adubação mineral em combinação com as doses de 0,4 e $6 \mathrm{t} \mathrm{ha}^{-1}$ do composto orgânico ocorrendo resultados mais expressivos com o uso da metade da dose recomendada de adubo químico no solo. A explicação pode estar no fornecimento complementar do K realizado por meio da adubação mineral. $\mathrm{O}$ fornecimento complementar foi responsável pela incorporação ao solo de $12,5 \mathrm{~kg}$ $\mathrm{ha}^{-1}$ de $\mathrm{K}_{2} \mathrm{O}$ nos sulcos de semeadura, podendo ter sido posteriormente lixiviado para a camada de $0,10-0,20 \mathrm{~m}$.

Analisando os teores de $\mathrm{K}$ obtidos para os tratamentos com composto orgânico decorrentes da combinação com a adubação mineral, verificou-se que os resultados se adequaram em um modelo quadrático, com maiores valores pelo incremento de composto orgânico a partir de $4 \mathrm{t} \mathrm{ha}^{-1}$ (Tabela 5). Para os teores de Ca no solo, maiores valores médios $\left(22,50 \mathrm{mmol}_{\mathrm{c}} \mathrm{dm}^{-3}\right)$ foram exibidos pela combinação testemunha (sem adubação mineral) mais a aplicação de $6 \mathrm{t} \mathrm{ha}^{-1}$ do composto orgânico (Tabela 5). Os teores de cálcio com uso do composto orgânico independente se combinados ou não com a adubação mineral apresentaram valores que se ajustaram de forma linear, com respostas negativas ao incremento do composto orgânico ao solo anterior a semeadura do feijoeiro de inverno.

Tabela 5. Desdobramento de interação composto orgânico e adubo mineral para os teores de K e Ca na camada de 0,10 - 0,20 m. Selvíria, Mato Grosso do Sul. Safra 2013.

\begin{tabular}{lccccc}
\hline \multirow{1}{*}{$\begin{array}{c}\text { Adubo Mineral } \\
\left(\mathrm{Kg} \mathrm{ha}^{-1}\right)\end{array}$} & \multicolumn{4}{c}{ Composto orgânico $\left(\mathrm{t} \mathrm{ha}^{-1}\right)$} & \multirow{2}{*}{ Equação } \\
\cline { 2 - 5 } & 0 & 2 & 4 & 6 & \\
\hline Testemunha & $0,62 \mathrm{~b}$ & $0,82 \mathrm{a}$ & $0,62 \mathrm{~b}$ & $0,80 \mathrm{~b}$ & n.s \\
$1 / 2$ dose recomendado & $0,90 \mathrm{a}$ & $0,75 \mathrm{a}$ & $1,00 \mathrm{a}$ & $1,12 \mathrm{a}$ & R.Q ${ }^{(1)}$ \\
\hline \multicolumn{5}{c}{ Ca mmol $\mathrm{dm}^{-3}$} \\
\hline Testemunha & $27,50 \mathrm{a}$ & $26,00 \mathrm{a}$ & $18,25 \mathrm{a}$ & $22,50 \mathrm{a}$ & R.L $\mathrm{L}^{(2)}$ \\
$1 / 2$ dose recomendado & $28,25 \mathrm{a}$ & $23,50 \mathrm{a}$ & $23,75 \mathrm{a}$ & $14,50 \mathrm{~b}$ & R.L $\mathrm{L}^{(3)}$
\end{tabular}

Médias seguidas pela mesma letra na coluna, não diferem entre si pelo teste de Tukey a $5 \%$ de probabilidade. ${ }^{(1)} Y=1,05-0,25 x+0,06 x^{2}, \quad(p<0,05), R^{2}=0,81 ;{ }^{(2)} Y=29,25-2,22 x \quad(p<0,05), R^{2}=0,51 ;{ }^{(3)} Y=32,75-4,10 x$, $(\mathrm{p}<0,01), \mathrm{R}^{2}=0,84{ }^{\text {n.s }}$ não significativo.

A adubação residual do composto orgânico melhorou os teores de Ca nas folhas de milho, constatando-se para a aplicação de $6 \mathrm{t} \mathrm{ha}^{-1}$ um teor de Ca nas folhas equivalente a 8,31 
$\mathrm{g} \mathrm{kg}^{-1}$. Essa dose seria suficiente para o fornecimento adequado do nutriente para a cultura do milho nas condições do solo estudado (Tabela 6).

Tabela 6. Média dos teores foliares de macronutrientes $\left(\mathrm{g} \mathrm{kg}^{-1}\right)$ do milho e índice de clorofila foliar (ICF), em função de doses do composto orgânico combinado ou não com adubação mineral em Selvíria, MS.

\begin{tabular}{lccccccc}
\hline \multirow{2}{*}{ Tratamento } & $\mathrm{N}$ & $\mathrm{P}$ & $\mathrm{K}$ & $\mathrm{Ca}$ & $\mathrm{Mg}$ & $\mathrm{S}$ & $\mathrm{ICF}$ \\
\cline { 2 - 7 } & $-----------------------\left(\mathrm{g} \mathrm{kg}^{-1}\right)---------------------$ & \\
\hline Composto Orgânico $\left(\mathrm{t} \mathrm{ha}^{-1}\right)$ & & & & & & & \\
0 & 25,67 & 2,84 & 13,31 & $7,75^{(1)}$ & 2,31 & $1,92^{(2)}$ & 52,13 \\
2 & 25,72 & 3,17 & 14,09 & 7,43 & 2,40 & 2,52 & 51,18 \\
4 & 26,92 & 2,66 & 14,00 & 7,78 & 2,31 & 2,18 & 53,12 \\
6 & 24,81 & 2,77 & 14,93 & 8,31 & 2,18 & 1,93 & 51,45 \\
\hline Adubo Mineral $\left(\mathrm{kg} \mathrm{ha}^{-1}\right)$ & & & & & & & \\
\hline Testemunha & 26,99 & $2,99 \mathrm{a}$ & 14,48 & 7,92 & 2,40 & $2,30 \mathrm{a}$ & 52,33 \\
1/2 dose Recomendado & 25,89 & $2,73 \mathrm{~b}$ & 13,68 & 7,71 & 2,20 & $1,97 \mathrm{~b}$ & 51,61 \\
\hline Teste F - (CO) & $1,43^{\mathrm{ns}}$ & $4,36^{\mathrm{ns}}$ & $0,79^{\mathrm{ns}}$ & $4,77^{*}$ & $0,30^{\mathrm{ns}}$ & $5,38^{* *}$ & $0,37^{\mathrm{ns}}$ \\
\hline Teste F (AM) & $0,38^{\mathrm{ns}}$ & $6,10^{*}$ & $1,13^{\mathrm{ns}}$ & $1,49^{\mathrm{ns}}$ & $1,56^{\mathrm{ns}}$ & $7,48^{*}$ & $0,26^{\mathrm{ns}}$ \\
\hline Teste F - CO x AM & $0,66^{\mathrm{ns}}$ & $3,83^{*}$ & $2,38^{\mathrm{ns}}$ & $51,71^{* *}$ & $0,18^{\mathrm{ns}}$ & $7,13^{* *}$ & $1,25^{\mathrm{ns}}$ \\
\hline DMS & 3,67 & 0,22 & 1,55 & 0,34 & 0,33 & 0,25 & 2,94 \\
\hline CV (\%) & 18,92 & 10,38 & 15,02 & 6,01 & 19,93 & 16,04 & 7,72 \\
\hline
\end{tabular}

Médias seguidas por mesma letra na coluna, para diferentes tratamentos, não diferem entre si pelo teste de Tukey a $5 \%$ de probabilidade. ${ }^{* *} \mathrm{e}^{*}$ : significativo a 1 e $5 \%$ de probabilidade pelo Teste de Tukey, respectivamente. ${ }^{\text {ns }}$ não significativo. Em que: DMS: diferença mínima significativa e CV: coeficiente de variação. ${ }^{(1)} \mathrm{Y}=0,0531 \mathrm{x}^{2}$ $-0,2172 \mathrm{x}+7,7255(\mathrm{p}<0,05),\left(\mathrm{R}^{2}=0,97\right) ;^{(2)} \mathrm{Y}=-0,0531 \mathrm{x}^{2}+0,3032 \mathrm{x}+1,9715(\mathrm{p}<0,01),\left(\mathrm{R}^{2}=0,77\right)$.

Tabela 7. Desdobramento das interações significativas para os teores de $\mathrm{P}, \mathrm{Ca}, \mathrm{S}$ nas análises nutricionais foliares do milho, em função do residual do composto orgânico e adubação mineral em Selvíria, MS.

\begin{tabular}{|c|c|c|c|c|c|}
\hline \multirow{2}{*}{ Adubo mineral $\left(\mathrm{kg} \mathrm{ha}^{-1}\right)$} & \multicolumn{4}{|c|}{ Composto orgânico $\left(\mathrm{t} \mathrm{ha}^{-1}\right)$} & \multirow{2}{*}{ Equação } \\
\hline & 0 & 2 & 4 & 6 & \\
\hline \multicolumn{6}{|c|}{$\mathrm{P}\left(\mathrm{g} \mathrm{kg}^{-1}\right)$} \\
\hline Testemunha & $2,97 \mathrm{a}$ & $3,60 \mathrm{a}$ & $2,64 a$ & $2,76 a$ & n.s \\
\hline $1 / 2$ dose recomendada & $2,72 \mathrm{a}$ & $2,75 b$ & $2,68 \mathrm{a}$ & $2,78 \mathrm{a}$ & n.s \\
\hline \multicolumn{6}{|c|}{$\mathrm{Ca}\left(\mathrm{g} \mathrm{kg}^{-1}\right)$} \\
\hline Testemunha & $9,62 \mathrm{a}$ & $6,81 b$ & $7,18 b$ & $8,06 a$ & R.Q $Q^{(1)}$ \\
\hline $1 / 2$ dose recomendada & $5,87 \mathrm{~b}$ & $8,06 \mathrm{a}$ & $8,37 \mathrm{a}$ & $8,56 a$ & R. $Q^{(2)}$ \\
\hline \multicolumn{6}{|c|}{$\mathrm{S}\left(\mathrm{g} \mathrm{kg}^{-1}\right)$} \\
\hline Testemunha & $1,77 \mathrm{a}$ & $3,14 \mathrm{a}$ & $2,33 a$ & $1,99 \mathrm{a}$ & R.Q $Q^{(3)}$ \\
\hline $1 / 2$ dose recomendada & $2,07 \mathrm{a}$ & $1,90 b$ & $2,04 \mathrm{a}$ & $1,88 \mathrm{a}$ & n.s \\
\hline
\end{tabular}

Cultura Agronômica, Ilha Solteira, v.25, n.4, p.387-400, 2016 
Os resultados dos teores de $\mathrm{S}$ nos tecidos foliares do milho se ajustaram a uma equação quadrática (Tabela 6). Assim, verificou-se aumento nos teores de enxofre até a aplicação de 2,4 t ha ${ }^{-1}$ do composto orgânico, contudo, contatou-se redução nos teores do nutriente em função do incremento de maiores doses do composto orgânico.

Analisando os desdobramentos da interação entre composto orgânico e metade da dose recomendada para a adubação mineral (Tabela 7), verificou-se efeito desta sobre os teores de $\mathrm{P}$, Ca e S encontrados nos tecidos foliares do milho. Quanto as concentrações de P e S, a combinação entre os tratamentos com adubação mineral da dose de $2 \mathrm{t} \mathrm{ha}^{-1}$ reduziram os teores dos nutrientes nos tecidos foliares da cultura. Assim, maiores resultados foram constatados para as testemunhas $\left(3,60 \mathrm{~g} \mathrm{~kg}^{-1}\right) \mathrm{e}\left(3,14 \mathrm{~g} \mathrm{~kg}^{-1}\right)$ frente à metade da dose mineral recomendada $\left(2,75 \mathrm{~g} \mathrm{~kg}^{-1}\right)$ e $\left(1,90 \mathrm{~g} \mathrm{~kg}^{-1}\right)$, respectivamente na dose de $2 \mathrm{t} \mathrm{ha}^{-1}$ de composto orgânico (Tabela 7).

Os resultados encontrados para as concentrações de Ca em função do uso do composto orgânico, independente da combinação com os tratamentos de adubo mineral, se ajustaram à um modelo quadrático de resposta. $\mathrm{O}$ teor de $\mathrm{Ca}$ nas folhas foi superior nas plantas, principalmente com a metade da dose de adubo químico.

Tabela 8. Média dos valores de Altura da planta (AP), altura de inserção de primeira espiga (AIE), diâmetro de colmo (DC), comprimento de espiga (CE), diâmetro de espiga (DE), diâmetro de sabugo (DS), massa cem grãos (M100) e produtividade de grãos (PROD) em função do residual das doses do composto orgânico combinado ou não com adubação mineral sobre a cultura do milho em Selvíria, MS.

\begin{tabular}{|c|c|c|c|c|c|c|c|}
\hline \multirow{2}{*}{ Tratamento } & AP & AIE & $\mathrm{DC}$ & $\mathrm{CE}$ & $\mathrm{DE}$ & DS & M100 PROD \\
\hline & \multicolumn{6}{|c|}{ 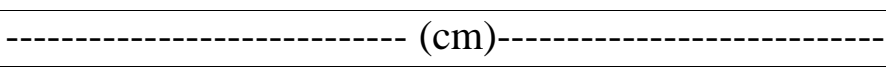 } & g $\mathrm{kg} \mathrm{ha}^{-1}$ \\
\hline \multicolumn{8}{|c|}{ Composto Orgânico $\left(\mathrm{t} \mathrm{ha}^{-1}\right)$} \\
\hline 0 & 231,02 & 101,40 & 2,20 & 17,63 & 4,54 & 2,91 & 24,663793 \\
\hline 2 & 232,08 & 103,20 & 2,17 & 18,36 & 4,61 & 2,97 & $24,09 \quad 4675$ \\
\hline 4 & 222,92 & 95,36 & 2,10 & 17,53 & 4,67 & 2,95 & 25,153953 \\
\hline 6 & 233,33 & 103,23 & 2,14 & 17,03 & 4,63 & 2,97 & 26,513762 \\
\hline \multicolumn{8}{|l|}{ Adubo Mineral $\left(\mathrm{kg} \mathrm{ha}^{-1}\right)$} \\
\hline Testemunha & 227,50 & 99,93 & 2,16 & 17,17 & 4,58 & 2,95 & $24,01 \mathrm{~b} 4044$ \\
\hline $1 / 2$ dose Recomendado & 232,18 & 101,66 & 2,14 & 18,10 & 4,64 & 2,95 & 26,20a 4047 \\
\hline Teste $\mathrm{F}-(\mathrm{CO})$ & $1,66^{\mathrm{ns}}$ & $2,85^{\mathrm{ns}}$ & $0,78^{\mathrm{ns}}$ & $1,18^{\mathrm{ns}}$ & $0,50^{\mathrm{ns}}$ & $0,59^{\mathrm{ns}}$ & $1,51^{\mathrm{ns}} 2,32^{\mathrm{ns}}$ \\
\hline Teste F - (AM) & $1,65^{\mathrm{ns}}$ & $0,61^{\mathrm{ns}}$ & $0,24^{\mathrm{ns}}$ & $3,38^{\mathrm{ns}}$ & $0,59^{\mathrm{ns}}$ & $0,10^{\mathrm{ns}}$ & $6,83^{*} 0,10^{\mathrm{ns}}$ \\
\hline Teste F - CO x AM & $1,00^{\mathrm{ns}}$ & $0,97^{\mathrm{ns}}$ & $0,99^{\mathrm{ns}}$ & $2,12^{\mathrm{ns}}$ & $1,91^{\mathrm{ns}}$ & $0,52^{\mathrm{ns}}$ & $0,77^{\mathrm{ns}} 2,82^{\mathrm{ns}}$ \\
\hline DMS - (AM) & 7,58 & 4,58 & 0,10 & 1,04 & 0,16 & 0,07 & $1,74 \quad 580,18$ \\
\hline $\mathrm{CV}(\%)$ & 4,49 & 6,89 & 6,32 & 8,06 & 4,83 & 3,53 & $9,46 \quad 19,65$ \\
\hline
\end{tabular}

Médias seguidas por mesma letra na coluna, para diferentes tratamentos, não diferem entre si pelo teste de Tukey a $5 \%$ de probabilidade. ${ }^{* *} \mathrm{e}^{*}$ : significativo a 1 e $5 \%$ de probabilidade pelo Teste de Tukey, respectivamente. ${ }^{\text {ns }}$ não significativo. Em que: DMS: diferença mínima significativa e CV: coeficiente de variação.

Cultura Agronômica, Ilha Solteira, v.25, n.4, p.387-400, 2016 
Não houve efeito residual do composto orgânico sobre a altura de planta (AP), altura de inserção de primeira espiga (AIE), comprimento de espiga (CE), diâmetro de espiga, colmo e sabugo (DE), (DC) e (DS) respectivamente, além dos componentes massa de 100 grãos e da produtividade de grãos de milho (Tabela 8). Neste aspecto, provavelmente as mudanças observadas nas características químicas do solo não foram suficientes para influenciar a produtividade das culturas.

Castoldi et al. (2011), avaliando o desempenho produtivo do milho submetido a fontes de adubação (mineral, orgânica com biofertilizante de suínos e organomineral), em Latossolo Vermelho eutroférrico de textura argilosa, não constataram efeito das fontes de adubação sobre a altura de planta, de inserção da espiga e diâmetro de espiga, indicando que a adubação mineral pode ser substituída por fontes orgânicas, sem que haja perdas na cultura. Entretanto, os autores mencionam que, os efeitos das fontes orgânicas sobre os componentes de produção não são totalmente conclusivos, sendo mais susceptíveis a alterações proporcionadas devido ao uso de fontes minerais.

Uma das hipóteses para os resultados pode estar nas doses adotadas para o ensaio experimental, estas seriam insuficientes para promover efeitos sobre os componentes de produção da cultura do milho, tendo seus efeitos ainda mais reduzidos em função do experimento se basear no efeito residual da aplicação do composto orgânico nas referidas doses. Cabe destacar também que, pelos resultados de fertilidade do solo na instalação do experimento, os valores nutricionais estavam adequados para o cultivo de feijão e posteriormente milho. Assim, pelos valores adequados obtidos para os teores foliares de nutrientes, o efeito dos tratamentos foram pouco significativos mesmo porque, as adubações de cobertura (feijoeiro e milho) foram baseadas em altas metas de produtividade, e portanto o $\mathrm{N}$ que poderia ser o limitante pelo uso dos tratamentos não foi para o adequado desenvolvimento das plantas.

O efeito residual da aplicação da metade da dose do adubo mineral sobre a cultura antecessora ao cultivo do milho alterou a massa de cem grãos de milho (Tabela 8). Para as demais características avaliadas não houve efeito da aplicação residual da metade da dose recomendada na cultura do feijoeiro, cultivada anteriormente ao milho.

\section{CONCLUSÃO}

O feijoeiro cultivado em SPD não responde ao composto orgânico aplicado na superfície do solo, mesmo quando combinado com metade da dose de adubação química recomendada na semeadura.

O resíduo do composto orgânico não influenciou os componentes produtivos e a nutrição da cultura do milho em sucessão ao feijão.

O adubo orgânico aplicado superficialmente é suficiente para promover alteração no teor de fósforo do solo depois do cultivo do feijão de inverno na camada de 0-0,10 m. Para a 
camada de 0,10-0,20 m de profundidade o composto orgânico altera apenas os teores de potássio e cálcio do solo.

\section{REFERÊNCIAS BIBLIOGRÁFICAS}

CANTARELLA, H; RAIJ, B. VAN; CAMARGO, C. Cereais. In: RAIJ, B. VAN; CANTARELLA, H; QUAGGIO, J. A.; FURLANI, A. M. C. Recomendações de calagem e adubação para o Estado de São Paulo. 2. ed. Campinas: IAC, 1997. p. 43-71. (Boletim técnico, 100).

CASTOLDI, G. COSTA, M. S. S. M.; COSTA, L. A. M.; PIVETTA, L. A. STEINER, F. Sistemas de cultivo e uso de diferentes adubos na produção de silagem e grãos de milho. Acta Scientiarum Agronomy, Maringá, v. 33, n. 1, p.139-146, 2011.

DAMATTO JUNIOR, E. R. Efeitos da adubação com composto orgânico na fertilidade do solo, desenvolvimento, produção e qualidade de frutos de bananeira 'Prata-anã' (Musa AAB). 2005. 70 f. Dissertação (Mestrado em Agronomia / Energia na Agricultura) Faculdade de Ciências Agronômicas, Universidade Estadual Paulista, Botucatu, 2005.

FERREIRA, D. F. Programa de análises estatísticas (Statistical Analysis Software) e planejamento de experimentos. Lavras: Universidade Federal de Lavras, 2003. Software. Disponível em: http:// www.ufla.br. Acesso em: 14 dez. 2014.

GUARESCHI, R. F.; PERIN, A.; ROCHA, A. C.; ANDRADE, D. N. Adubação com cama de frango e esterco bovino na produtividade de feijão azuki (Vigna angularis). Revista Agrarian, Dourados, v. 6, n. 19, p.29-35, 2013.

KROB, A. D.; MORAES, S. P.; SELBACH, P. A.; BENTO, F. M.; CAMARGO, F. A. O. Propriedades químicas de um Argissolo tratado sucessivamente com composto de lixo urbano. Ciência Rural, Santa Maria, v. 41, n. 3, p.433-439, 2011.

MALAVOlTA, E.; VITTI, G. C.; OLIVEIRA, S. A. Avaliação do estado nutricional das plantas: princípios e aplicações. 2.ed. Piracicaba: Associação Brasileira para Pesquisa da Potassa e do Fosfato, 1997. 319 p.

MORAES, M. T.; SILVA, V. R.; ARNUTI, F. Resíduos líquidos de efluentes de agroindústria de carnes na produtividade de girassol. Enciclopédia Biosfera, Goiânia, v. 8, n. 14, p.843853, 2012.

RAIJ, B. Van; CANTARELLA, H.; QUAGGIO, J. A. FURLANI, A. M. C. Recomendações de adubação e calagem para o estado de São Paulo. 2.ed. Campinas: Instituto Agronômico Campinas, 1997. 285 p.

RAIJ, B. Van; ANDRADE, J. C.; CANTARELlA, H.; QUAGGIO, J. A. Análise química para avaliação da fertilidade de solos tropicais. Campinas: Instituto Agronômico, 2001. $284 \mathrm{p}$.

Cultura Agronômica, Ilha Solteira, v.25, n.4, p.387-400, 2016 
RIBEIRINHO, V. S.; MELO, W. J.; SILVA, D. H.; FIGUEIREDO, L. A.; MELO, G. M. P. Fertilidade do solo, estado nutricional e produtividade de girassol, em função da aplicação de lodo de esgoto. Pesquisa Agropecuária Tropical, Goiânia, v. 42, n. 2, p.166-173, 2012.

SARTOR, L. R.; ASSMANN, A. L.; ASSMANN, T. S.; BIGOLIN, P. E.; MIYAZAWA, M.; CARVALHO, P. C. F. Effect of swine residue rates on corn, common bean, soybean and wheat yield. Revista Brasileira de Ciência do Solo, Viçosa, v. 36, n. 2, p.661-669, 2012.

VERAS, L. R. V.; POVINELLI, J. A vermicompostagem do lodo de lagoas de tratamento de efluentes industriais consorciada com composto de lixo urbano. Revista Brasileira de Engenharia Sanitária e Ambiental. Rio de Janeiro, v. 9, n. 3, p.218-224, 2004.

VIDIGAL, S. M.; SEDIYAMAI, M. A. N.; PEDRO-SAI, M. W.; SANTOS, M. R. Produtividade de cebola em cultivo orgânico utilizando composto à base de dejetos de suínos. Horticultura Brasileira, Brasília, v. 28, n. 2, p.168-173, 2010. 